\title{
Utilization of Saliva as a Diagnostic Fluid in Determination of Oral Cancer
}

${ }^{1}$ Sonal Pratapsingh Vahanwala, ${ }^{2}$ Soumyo Mukherji

\begin{abstract}
Today's world technology has evolved and we have been able to evaluate certain phenomenon that occurs before manifestation of observable clinical symptoms. Every health care worker has a dream of a perfect diagnosis so that correct service whether medical or surgical, care can be facilitated to the patient. Cancer is one such disease where tracking the tell-tale signs is essential. The one factor behind oral cancer's high mortality is the challenge in its early detection. Despite the scepticism in the scientific community and the conservatism of the patients, saliva seems to emerge as a valuable tool in cancer diagnostics and mass screening of the population. An attempt to integrate the simultaneous testing of different salivary molecular markers in order to raise the possibility of an accurate diagnosis by simply using micro- and nanoelectricmechanical systems biosensors is on the way raising much hope in its future applications.
\end{abstract}

Keywords: Saliva, Oral cancer, Diagnostic fluid.

How to cite this article: Vahanwala SP, Mukherji S. Utilization of Saliva as a Diagnostic Fluid in Determination of O ral C ancer. Int J Head Neck Surg 2014;5(1):15-21.

\section{Source of support $\mathrm{Nil}$}

Conflict of interest None

\section{INTRODUCTION}

The human body is riddled with complex phenomena going on in different somatic systems. These are well programmed and seem to be systematic. It is left to the researchers to pick up the clues to predict the disease and heal th of the population. But, in today's world technology has evolved and we have been able to evaluate certain phenomenon that occurs before manifestation of observable clinical symptoms. Every health care worker has a dream of a perfect diagnosis so that correct service whether medical or surgical, care can be facilitated to the patient. Cancer is one such disease where tracking the tell-tale signs is essential. The one factor behind oral cancer's high mortality is the challenge in its early detection.

\footnotetext{
1,2 Professor

${ }^{1}$ Department of Oral Medicine and Radiology, Dr DY Patil Dental College and Hospital, Navi Mumbai, Maharashtra, India

${ }^{2}$ Department of Biosciences and Bio-Engineering, Indian Institute of Technology, Mumbai, Maharashtra, India

Corresponding Author: Soumyo Mukherji, Professor Department of Biosciences and Bio-Engineering, Indian Institute of Technology, Mumbai, Maharashtra, India, Phone: 9820372903, e-mail: drvahanwalasonal@gmail.com
}

\section{CURRENT SCENARIO IN ORAL CANCER SCREENING}

The most definitive procedure for oral cancer diagnosis is a scalpel biopsy followed by careful histopathological evaluation by a qualified pathologist. For this to be an effective procedure, it requires three consecutive visits to the dentist and physician's office, biopsy by the licensed health care provider and a pathologist's eval uation.

Detection of an oral cancer at stage I will carry a prognosis of $80 \%$ survival, while the same lesion at stage III carries a $20 \%$ survival. This is a dramatic difference that affects not only the quality of life for the patient but have significant savings on the heal th care costs.

Researchers have been looking for al ternative approaches to biopsy, with the hope to find a test for oral cancer detection that is similar to the Papanicolaou smear, which has significantly improved the mortality in cases of cervical cancer. Since most oral cancers arise as asymptomatic small lesions, formal diagnosis procedures begin only when the clinician or patient notices abnormal tissues. ${ }^{1} \mathrm{M}$ icroscopic investigation of the progressive cancer is often conducted too late for any further intervention. ${ }^{2}$ It is al so impractical to use imaging techniques for cancer screening since they are time-consuming and expensive. These techniques are typically used for confirmation due to their lack of sensitivity toward small lesions. $^{3}$

Studies have demonstrated that good positive predictive values can be achieved by oral cancer tissue staining with toluidine blue. ${ }^{4,5}$ However, extensive experience is required in applying this technique and in interpreting its results. Exfoliative cytology may be a less invasive method for oral cancer detection ${ }^{6}$ but exfoliated cancer cells tend to correlate with tumor burden and lower rates of detection are seen in those with minimal or early disease. M any DNA markers, like TP53, HPV EBV genomic sequence, have been studied. Cytokeratins have been used for RNA diagnostics, while squamous cell carcinoma, CD 44, cytokeratin 19 fragments and telomerase have been used as protein markers. ${ }^{7,8}$ However, none of them is able to identify squamous cell carcinoma.

\section{SALIVA AS A DIAGNOSTIC FLUID}

The oral cavity is the 'gateway to our body.' M ore specifically speaking, saliva is a mirror of the body. The ability 
to utilize saliva to monitor the health and disease state of an individual is a highly desirable goal. However, saliva diagnostics is a 'late bloomer', since only recently has there been a growing appreciation of saliva as a mirror of the body which can reflect virtually the entire spectrum of normal and disease states.

Saliva includes tissue levels of natural substances and a large variety of molecules introduced for therapeutic, dependency or recreational purposes. The content also depends on emotional status, immunological status, neurological effects and nutritional and metabolic influences.

Whole saliva is the product of the secretions of the three major salivary glands (parotid, submandibular, sublingual) and the numerous minor salivary glands mixed with gingival crevicular fluid, bronchial and nasal secretions, blood constituents from wounds or bleeding gum, bacteria, viruses, fungi, exfoliated epithelial cells and food debris. Saliva has been proposed and used as a diagnostic medium, because it is easily accessible and its collection is noninvasive, not time-consuming, inexpensive, requires minimal training and can be used for the mass screening of large population samples. Whole saliva can be collected with or without stimulation. Stimulation can be performed with masticatory movements or by gustatory stimulation (citric acid). Stimulated saliva, although, it can be collected in larger quantities. Unsti mulated sal iva can be collected by merely spitting in a test tube or by leaving sal iva drool from the lower lip and it is more often used for the diagnosis or follow-up of systemic diseases.

A dvantages of saliva for diagnostics are as follows:

1. Colorless liquid in contrast to blood (which can undergo change and can compromise results).

2. Relatively safe, with no use of invasive devices like the needles.

3. Can be procured easily, does not require any specialized equipment or technician's expertize.

4. Salivais easier to handl efor diagnostic procedures because it does not clot, thus lessening the manipulations required.
5. It has better sensitivity and specificity than reference work done with blood samples.

Disadvantages: A major drawback to the use of saliva as a diagnostic fluid has been the notion that informative analyses are generally present in lower amounts in saliva than in serum.

It is riddled with bacteria and other detritus that would yield adulterated samples incapable of generating reliable and reproducible results.

Saliva has long been used for the monitoring of drug abuse (drugs and addictive substances), such as cocaine, heroin, amphetamine, barbiturates, etc. M oreover, salivary testing has been largely performed for the diagnosis of HIV infection. A nalysis of salivary parameters, such as salivary flow rate, pH, buffer capacity, Lactobacillus, and yeast content, presence of IgG, IgM and anti- L a autoantibodies and raised protein levels, such as that of lactoferrin and cystatin $\mathrm{C}$ as has been proposed for the diagnosis of Sjogren's syndrome. Concerning cancer diagnostics and follow-up altered levels of certain mRNA molecules have been detected in saliva in oral cancer patients and of certain proteins in several cancers.

Studies done on saliva for detection of breast cancer are as follows:

- Salivary picture in breast cancer: HER 2-It is found on the surface of regularly growing cells. Overexpression of this factor causes uncontrolled cell growth, more common in breast cells.

- Epidermal growth factor (EGF): It is a small protein known to stimulate tumor cells. A salivary study of this factor showed higher levels in women with breast cancer. Testing for proteins associated with EGF pathway appears to be promising in detection of breast cancer.

- Erb and CA 15-3: Studies have shown that these are in the proportion of 45 to $50 \%$ higher in women with breast cancer than those without. Salivary erb tests were able to detect $87 \%$ of the women with breast cancer.

\begin{tabular}{|c|c|c|}
\hline \multicolumn{3}{|c|}{ Saliva for molecular detection of oral cancer (review of literature) } \\
\hline Year & Reference & Study findings \\
\hline 2000 & $\begin{array}{l}\text { Liao PJ , Chang YC, Huang MF, Tai KW, Chou MY. } \\
\text { Mutation of p53 gene codon } 63 \text { in saliva as a } \\
\text { molecular marker for oral squamous cell carcinomas. } \\
\text { Oral Oncol 2000;36(3):272-276. } .^{9}\end{array}$ & $\begin{array}{l}\text { Claimed that exon } 4 \text { codon } 63 \text { of the p53 gene is mutated in } \\
\text { salivary DNA from five of eight (i.e. } 62.5 \% \text { ) oral cancer patients. } \\
\text { Five of } 27 \text { control subjects (i.e. } 18.5 \% \text { ) had similar } \\
\text { mutations in their p53 gene. }\end{array}$ \\
\hline 2001 & $\begin{array}{l}\text { El-Naggar AK, Mao L, Staerkel G, et al. Genetic hetero- } \\
\text { genecity in saliva from patients with oral squamous } \\
\text { carcinomas: implications in molecular diagnosis } \\
\text { and screening. J Mol Diagn } 2001 ; 3(4): 164-170 .{ }^{10}\end{array}$ & $\begin{array}{l}\text { Demonstrated genetic heterogenicity in saliva from patients with } \\
\text { oral squamous cell carcinoma and suggested the use of epithelial } \\
\text { cells in saliva from patients with head and neck squamous } \\
\text { tumorogenesis for genetic analysis. }\end{array}$ \\
\hline 2004 & $\begin{array}{l}\text { Hu S, Denny P, et al. Differentially expressed protein } \\
\text { markers in human submandibular and sublingual } \\
\text { secretions. Int J Oncol 2004;25(5):1423-1430. }{ }^{11}\end{array}$ & $\begin{array}{l}\text { Again a similar approach was conducted on submandibular and } \\
\text { sublingual saliva by method of comparative proteome analysis. }\end{array}$ \\
\hline
\end{tabular}


Contd.

2005 J iang WW, Masayesva B, Zahurak M, et al. Increased mitochondrial DNA content in saliva associated with head and neck cancer. Int J Cancer 2005;117(4): $605-610 .{ }^{12}$

2005 Zhao M, Rosenbaum E, Carvalho AL, et al. Feasibility of quantitative PCR-based saliva rinse screening of HPV for head and neck cancer. Int J Cancer 2005;117(4): 605-610. ${ }^{13}$

2006 Philips C. Rinse and spit. Saliva as a cancer biomarker source. In NCI Cancer Bulletin 2006;3-5. ${ }^{14}$

2005 Hu S, Xie Y, Ramachandran P, et al. Large-scale identification of proteins in human salivary proteome by liquid chromatography/mass spectrometry and twodimensional gel electrophoresis mass spectrometry. Proteomics 2005;5(6):1714-1728. ${ }^{15}$
Reported the increase of mitochondrial DNA content in saliva of head and neck cancer patients.

Quantitative analyzed of HPV 16 DNA in salivary rinses enables detection of HPV-related head and neck cancer. However, these authors cautioned that specific limitations exist that prevent the application of this as a screening technique for a broad population. University of California, Los Angeles (UCLA), at a laboratory, is utilizing. Research platforms toward the global identification of disease signatures in saliva. The premise of their approach is that serum contents, such as disease biomarkers are largely present in the saliva, thus rendering oral fluid a logical source to harness disease biomarkers. They employ both a proteome-wide as well as a genome-wide approach toward the identification of disease biomarkers and signatures.

They have already identified 309 distinct proteins in human whole saliva using 2D gel electrophoresis mass spectrometry and shotgun proteomics.
A $n$ increasing number of systemic diseases and conditions have been show $n$ to be reflected diagnostically in saliva. Along with these developments are technology advancements that have overcome barriers to the widespread implementation of salivary diagnostics. These barriers include technological problems related to achieving high sensitivity, high specificity, miniaturization, high throughput (that is assay a large number of samples concurrently), automation, portability, low cost, high functionality and speed; overcoming them has enabled researchers to detect and measure multiple disease markers.

Salivary contents in HFN tumors: In order to utilize the full diagnostic potential of saliva, one needs to decipher and catalog the informative components comprehensively. Comparison of such a catalog with a disease population will reveal diagnostic signatures that can discriminate between normal individuals and those with disease. The salivary proteome presents one such resource. ${ }^{16}$

Cancer-related genetic alterations identified in bodily fluids: In the development of neoplastic disease, progressive genotypic and phenotypic alterations, such as the activation of protoncogenes and oncogenes and inactivation of tumor suppressor genes associated with tumorigenesis are detected in the affected cells, establishing the model of multistep tumorigenesis. ${ }^{17}$ It has been show $n$ that identical mutations can be identified in bodily fluids draining a tumor, ${ }^{18}$ but also lately in bodily fluids secreted away from the initial point where a solid tumor is developing. ${ }^{19,20}$ Nucleic acids and proteins related to cancer cells have been detected in plasma/serum, ${ }^{21,22}$ urine, ${ }^{23,24}$ saliva, ${ }^{25,26}$ broncho-alveolar lavage fluid, cerebrospinal fluid ${ }^{27}$ and other bodily fluids. These nucleic acids and proteins have been used as molecular markers for the early diagnosis of the disease, ${ }^{26-29}$ recurrence markers survival and metastasis predictors ${ }^{30,31}$ and decide the therapeutic approach. ${ }^{32,33}$

Speculations about possible mechanisms that lead to the presence of genotypic and phenotypic markers in the saliva: Cell-free nucleic acids and proteins in sal iva may be derived from serum or can be locally produced. ${ }^{34}$ Serum derived nucleic acids and proteins in the saliva may be part of the normal salivary secretion (by the acinar cells) ${ }^{35}$ or come there either via intracellular routes, such as active transport or passive diffusion ${ }^{36}$ from the serum to saliva across cell membranes or extracellular routes, such as ultrafiltration through tight junctions ${ }^{37}$ or as constituents of the outflowing gingival crevicular fluid.

Cell-free nucleic acids and proteins in saliva however can be locally produced by cell necrosis, lysis or apoptosis and trauma and may even be actively released by normal epithelial or cancerous cells. Cell necrosis is a possible mechanism leading to the release of cell free nucleic acids and proteins in the saliva and this idea is also supported by the large amount of DNA in the plasma of patients with cancers in an advanced stage. Moreover, evidence exists concerning the presence of cell-free nucleic acids and proteins in apoptotic bodies ${ }^{38}$ which also protect these molecules from degradation. ${ }^{39}$ The active release of these molecules in exosomes or microvesicles is another strong possibility. ${ }^{40}$ Exosomes or microvesicles are released by living cells. They are membrane vesicles, 40 to $100 \mathrm{~nm}$ in diameter, ${ }^{41}$ originating from the endoplasmic reticulum and are released when fused with the cell membrane. They contain mRNA, ${ }^{42}$ miRNA $^{43}$ and proteins ${ }^{44}$ and are thought to play a role in the cell-free intercellular communication. ${ }^{45-47}$ Refer the bel ow table for ease of understanding. 


\section{Mechanisms that lead to the Presence of Genotypic and Phenotypic Markers in Saliva}

Cell-free nucleic acids and proteins in saliva (diagrammatic representation):

\begin{tabular}{ll}
\hline Serum derived & Locally produced \\
\hline Normal salivary secretion & Cell necrosis, lysis \\
Passive diffusion & Apoptosis \\
Active transport & Trauma \\
Ultrafiltration through & Active release \\
tight junctions & \\
Outflow of crevicular fluid & \\
\hline
\end{tabular}

Salivary markers for oral cancer detection: Molecular markers for the diagnosis of OSCC can be quested in three levels: (1) changes in the cellular DNA, (2) altered mR NA transcripts and (3) altered protein markers.

- Changes in the cellular DNA: Typical changes in the host DNA of dysplastic or cancer cells include point mutations, deletions, translocations, amplifications and methylations, cyclin D1, epidermal growth factor receptor (EGFR), microsatellite instability and HPV presence.

Allelic loss on chromosomes $9 p$ has been observed in OSCC. ${ }^{48} \mathrm{M}$ itochondrial DNA mutations have also been useful targets to detect exfoliated OSCC cells in saliva. They have been identified in $46 \%$ of head and neck cancers. The same mitochondrial DNA mutations were detected in $67 \%$ of saliva samples from OSCC patients by direct sequencing alone. ${ }^{49}$ p53 gene mutations are also present in approximately one-half of head and neck cancers. ${ }^{50,51} \mathrm{U}$ sing plaque hybridization, B oyle et al ${ }^{51}$ identified tumor specific p53 mutations in $71 \%$ saliva samples from patients with head and neck cancer.

Promoter hypermethylation of several genes has been reported in head and neck cancer. R osas et al identified aberrant methylation of at least one of three genes (p16, M GM T or DA P-K ) in OSCC. A bnormal promoter hypermethylation was also detected in the matched saliva sample in $65 \%$ of OSCC patients. ${ }^{52}$

Cyclin D1 gene amplification has been found to be associated with poor prognosis in OSCC..$^{53}$ In another study, Ki67 markers were increased, while 8-oxoguanine DNA glycosylase, phosphorylated-Src and mammary serine protease inhibitor (M aspin) were found decreased in the sal iva of patients with OSCC. ${ }^{54}$

Microsatellite alterations of DNA were also observed in the saliva of patients with small cell lung cancer. ${ }^{55}$ In the same study, it was further demonstrated that $93 \%$ of the patients with microsatellite instability in tumor DNA also had similar microsatellite alterations in the corresponding plasma DNA.
The presence of HPV (human papilloma virus) and Epstein-B arr virus genomic sequences have been identified as possible DN A molecular markers in detecting OSCC and tumor progression. ${ }^{56,57}$

\section{Altered mRNA Transcripts}

For several years, RNA was believed to be quickly degraded in saliva due to the various R N A ses that the saliva contains. ${ }^{58}$ Despite the opposite reports, ${ }^{59}$ cell-free RNA molecules, however, seem to exist in saliva both intact but also fragmented ${ }^{60} \mathrm{~A} n$ intriguing question that remains to be answered is the mechanism by which mRNA in saliva is protected by degradation. A speculation is that salivary mRNA is contained in apoptotic bodies 39,40 or actively released in exosomes or microvesicles. ${ }^{42,44,46} \mathrm{~L}$ ately, microR N A s, small RNA molecules, 18 to 24 molecules in length, which seem to regulate transcription were also discovered existing in saliva. ${ }^{61-63}$

mR N A detection in saliva has been extensively reported enabling body fluid identification in forensic medicine. ${ }^{64,65}$ M oreover, mRNA markers in the saliva have been proposed for the diagnosis of primary Sjögren's syndrome ${ }^{66}$ and for the identification of sleep drive both in flies humans. ${ }^{67}$

Various mRNA molecules were found upregulated in the saliva of patients suffering from OSCC by the team of $\mathrm{Li}$ et al. ${ }^{26}$ Seven mR N A molecules transcripts of the following: 1. Interleukin 8 (IL -8) playing a role in angiogenesis, replication, calcium-mediated signaling pathway, cell adhesion, chemotaxis, cell cycle arrest, immune response.

2. Interleukin 1B (IL-1B) which takes part in signal transduction, proliferation, inflammation and apoptosis.

3. DUSP1 (dual specificity phosphatase 1 ) with a role in protein modification, signal transduction and oxidative stress.

4. H3F $3 \mathrm{~A}$ ( $\mathrm{H} 3$ histone, family $3 \mathrm{~A}$ ) having a DNA binding activity.

5. OAZ1 (ornithine decarboxylase antizyme 1) taking part in polyamine biosynthesis.

6. $\mathrm{S} 100 \mathrm{P}$ ( $\mathrm{S} 100$ calcium binding protein $\mathrm{P}$ ) with a role in protein binding and calcium ion binding.

7. SAT (spermidine/spermine N1-acetyltransferase) which takes part in enzyme and transferase activity-were found significantly elevated in OSCC patients rather than in heal thy controls. ${ }^{47}$

\section{Altered P rotein Markers}

Several salivary protein markers for OSCC have been investigated in various studies and have shown relatively moderate sensitivity and specificity values rel ative to prognosis prediction. 
For example, defensins are peptides which possess antimicrobial and cytotoxic properties. They are found in the azurophil granules of polymorphonuclear leukocytes. ${ }^{68,69}$ Elevated levels of salivary defensin-1 were found to be indicative for the presence of OSCC, since higher concentrations of salivary defensin- 1 were detected in patients with OSCC compared with healthy controls. ${ }^{70}$

In another study, soluble CD $44^{71}$ was found to be elevated in the majority of patients with OSCC and distinguished cancer from benign disease with high specificity. Whereas the solCD 44 test lacks sensitivity by itself, methylation status of the CD 44 gene seems to compl ement the solCD 44 test and provides very high sensitivity and specificity for the detection of OSCC.

St J ohn et al ${ }^{25}$ investigated whether IL -6 and/or IL - 8 could serve as informative biomarkers for OSCC in saliva. IL -8 was detected at higher concentrations in sal iva, while IL -6 was detected at higher concentrations in serum of patients with OSCC. Thus, they concluded that IL - 8 in saliva and IL-6 in serum hold promise as biomarkers for OSCC.

A group of leading researchers ${ }^{26,47}$ using new and sophisticated approaches, such as, Luminex Multianalyte Profiling (XM AP) technology, shotgun proteomics, capillary reversed-phase liquid chromatography with quadruple time-of-flight mass spectrometry and matrix-assisted laser desorption/ionization-mass spectrometry (M A LDI-M S), has contributed significantly in recent years to the research in saliva for cancer diagnosis. Their studies have shown that saliva contains proteins that may serve as biomarkers for OSCC, since 46 peptides/proteins were found at significantly different levels betw een the OSCC and control groups. For example, A rellano-G arcia et al using L uminex xM A P technology showed that both IL-8 and IL-1b were expressed at significantly higher levels in OSCC subjects.

\footnotetext{
Molecular markers for the diagnosis of oral

squamous cell carcinoma

Changes in the cellular DNA

- Allelic loss on chromosomes 9p mitochondrial DNA mutations

- p53 gene mutations

- Promoter hypermethylation of genes

(p16, MGMT or DAP-K)

- Cyclin D1 gene amplification

- Increase of Ki67 markers

- Microsatellite alterations of DNA

- Presence of HPV

Altered mRNA transcripts

- Presence of IL-1B

- DUSP1 (dual specificity phosphatase 1)

- H3F3A (H3 histone, family 3A)

- OAZ1 (ornithine decarboxylase antizyme 1)

- S100P (S100 calcium binding protein P)

- SAT (spermidine/spermine N1-acetyltransferase)
}

Contd.

Altered protein markers

- Elevated levels of defensin-1

- Elevated CD44

- Elevated IL-6 and IL-8

- Inhibitors of apoptosis (IAP)

- Squamous cell carcinoma associated antigen (SCC-Ag)

- Carcinoembryonic antigen (CEA)

- Carcinoantigen (CA19-9)

- CA128

- Serum tumor marker (CA125)

- Intermediate filament protein (Cyfra 21-1)

- Tissue polypeptide specific antigen (TPS)

- Reactive nitrogen species (RNS)

- 8-OHdG DNA damage marker

- Lactate dehydrogenase (LDH)

- Immunoglobulin (IgG)s-IgA

- Insulin growth factor (IGF)

- Metalloproteinases MMP-2 and MMP-11

\section{CONCLUSION}

Saliva, a biofluid seems to hold a promise as a diagnostic fluid as compared to blood in parameters, such as sensitivity, specificity and applicability of the method, cost and duration of the procedure, with superb patient compliance. Due to the recent advances and emerging technologies in molecular biology new molecular markers (DNA, RNA and protein markers) have been discovered existing in the saliva in measurable quantities. OSCC can be diagnosed with high sensitivity and specificity by merely testing saliva samples from the subjects. This does not of course undermine the value of screening tests by visual examination neither the importance of the tissue biopsy.

We still need to explore and exploit technologies to get the best outcome of the laboratory tests. Despite the scepticism in the scientific community and the conservatism of the patients, saliva seems to emerge as a valuable tool in cancer diagnostics and mass screening of the population. A $n$ attempt to integrate the simultaneous testing of different salivary molecular markers in order to raise the possibility of an accurate diagnosis by simply using micro- and nanoelectromechanical systems biosensors is on thew wy raising much hopein its future applications.

Finally, since the present methods are not ready for immediate clinical use as diagnostic tools, much work is necessary and it can be envisaged that simple, fast, portable and cost-effective clinical diagnostic systems could be available in the near future.

\section{REFERENCES}

1. The international statistical classification of diseases and related heal th problems. World Health Organization; Geneva 1992.

2. A merican Cancer Society. Cancer Facts and Figures 2007. A tlanta: A merican Cancer Society 2007. 
3. Ferlay J, Bray F, Pisani P, Parkin DM. Globocan 2000, cancer incidence, mortality and prevalence worldwide, Version 1.0. Lyon: IA RC Press; 2001.

4. Peacock S, Pogrel A, Schmidt B L. Exploring the reasons for delay in treatment of oral cancer. A m D entA ssoc 2008;139:1346-1352.

5. Schantz SP. B iologic markers, cellular differentiation and metastatic head and neck cancer. Eur A rch O torhinolaryngol 1993;250: 424-428.

6. Schantz SP. Carcinogenesis, markers, staging and prognosis of head and neck cancer. Curr Opin Oncol 1993;5:483-490.

7. Sidransky D. Emerging molecular markers of cancer. $\mathrm{N}$ at Rev Cancer 2002;3:210-219.

8. Ellison M D, C ampbell BH. Screening for cancer of the head and neck: Addressing the problem. Surg Oncol Clin N Am 1999;8: 725-734.

9. Fedele S. Diagnostic aids in the screening of oral cancer. Head Neck Oncol 2009;30:1-5.

10. Trullenque-Eriksson A, M unoz-Corcuera M , Campo-Trapero J, Cano-Sánchez J, B ascones-M artínez A. A nalysis of new diagnostic methods in suspicious lesions of the oral mucosa. M ed Oral Patol Oral Cir Buccal 2009;14:E210.

11. Dolan RW, Vaughan CW, Fuleihan N. Symptoms in early head and neck cancer: An inadequate indicator. Otolaryngol Head Neck Surg 1998;118:463-467.

12. Sankila R, Coll EC. Evaluation and monitoring of screening program. L uxembourg: Office for the Official Publication of the European Communities 2001;243-254

13. Warnakulasuriya S, Nanayakkara BG. Reproducibility of an oral cancer and precancer detection program using a primary health care model in Sri L anka. Cancer Detect Prev 1991;15:331-334.

14. ZakzerwskaJ M, Hindle I, Speight PM . Practical considerations for the establishment of an oral cancer screening programme. Commun Dent Health 1993;10(Suppl 1):79-85.

15. Onofre MA, Sposto MR, Navarro CM. Reliability of toluidine application in the detection of oral epithelial dysplasia and in situ and invasive squamous cell carcinomas. O ral Surg Oral M ed Oral Pathol Oral Radiol Endod 2001;91:535-540.

16. Zhang $L$, Williams $M$, Poh $C F$, et al. Toluidine blue staining identifies high-risk primary oral premalignant lesions with poor outcome. Cancer Res 2005;65:8017-8021.

17. Christian DC. Computer-assisted analysis of oral brush biopsies at an oral cancer screening program. J A m DentA ssoc 2002;133: 357-362.

18. M ehrotra R, Hullmann $M$, Smeets $R$, R eichert TE, D riemel 0 . Oral cytology revisited. J Oral Pathol Med 2009;38:161-166.

19. Kerr AR, Sirois DA, E pstein JB. Clinical evaluation of chemiluminescent lighting: $\mathrm{A} n$ adjunct for oral mucosal examinations. J Clin Dent 2006;17:59-63.

20. Epstein J B, Silverman S J r, Epstein J D, L onky SA, B ride M A. A nalysis of oral lesion biopsies identified and evaluated by visual examination, chemiluminescence and tolouidine blue. Oral Oncol 2008;44:538-544.

21. Onizawa K, Saginoya H, Furuya Y, Yoshida H. Fluorescence photography as a diagnostic method for oral cancer. Cancer $L$ ett 1996;108:61-66.

22. K ujan O, Glenny A M , Oliver R, Thakker N, Sloan P. Screening programmes for the early detection and prevention of oral cancer. A ust Dent J 2009;54:170-172.

23. Omar K, G lenny A, D uxbury J, Thakker N, Sloan P. Evaluation of screening strategies for improving oral cancer mortality: A cohrane systematic review. J Dent E duc 2005;69:255-265.

24. Farber $\mathrm{E}$. The multistep nature of cancer development. Cancer Res 1984;44:4217-4223.
25. Bigler LR, Streckfus CF, Dubinsky WP. Salivary biomarkers for the detection of malignant tumors that are remote from the oral cavity. Clin Lab M ed 2009;29:71-85.

26. Streckfus $C, B$ igler $L$, Dellinger $T$, D ai $X, K$ ingman $A$, Thigpen $J \mathrm{~T}$. The presence of solublec-erbB -2 in saliva and serum among women with breast carcinoma: A preliminary study. Clin Cancer Res 2000;6:2363-2370.

27. Schmidt $B$, Engel $E, C$ arstensen $T$, et al. Q uantification of free RNA in serum and bronchial lavage: A new diagnostic tool in lung cancer detection? L ung Cancer 2005;48:145-147.

28. Kopreski MS, Benko FA, Gocke CD. Circulating RNA as a tumor marker: Detection of $5 T 4$ mRNA in breast and lung cancer patient serum. A nn NY A cad Sci 2001;945:172-178.

29. Hasselmann DO, Rappl G, Rössler M, U gurel S, Tilgen W, Reinhold U. Detection of tumor-associated circulating mRNA in serum, plasma and blood cells from patients with disseminated malignant melanoma. Oncol Rep 2001;8:115-118.

30. Bryzgunova OE, SkvortsovaTE, K ol esnikova EV, et al. I solation and comparative study of cell-free nucleic acids from human urine. A nn NY A cad Sci 2006;1075:334-344.

31. Yoneda $\mathrm{K}$, lida $\mathrm{H}$, Endo $\mathrm{H}$, et al. Identification of cystatin SN as a novel tumor marker for colorectal cancer. Int J Oncol 2009; 35:33-40.

32. St John M, Li Y, Zhou X, et al. Interleukin 6 and interleukin 8 as potential biomarkers for oral cavity and oropharyngeal squamous cell carcinoma. A rch Otolaryngol Head Neck Surg 2004;130:929-935.

33. Li Y, St J ohn M A, Zhou X, et al. Salivary transcriptome diagnostics for oral cancer detection. Clin Cancer Res 2004;10:84428450 .

34. de Bont JM, van Doorn J, Reddingius RE, et al. Various components of the insulin-like growth factor system in tumor tissue, cerebrospinal fluid and peripheral blood of pediatric medulloblastoma and ependymoma patients. IntJ Cancer 2008; 123:594-600.

35. Johnson PJ, Lo Y M. Plasma nucleic acids in the diagnosis and management of malignant disease. Clin Chem 2002;48: 1186-1193.

36. Neves A F, A raújo TG, Biase WK, et al. Combined analysis of multiple mRNA markers by RT-PCR assay for prostate cancer diagnosis. Clin Biochem 2008;41:1191-1198.

37. Honma $H, K$ anda $T$, I to $H$, et al. Squamous cell carcinomaantigen messenger RNA level in peripheral blood predicts recurrence after resection in patients with esophageal squamous cell carcinoma. Surgery 2006;139:678-685.

38. El-A bd E, El-Tahan R, Fahmy L, et al. Serum metastases mR NA is an important survival predictor in breast cancer. $\mathrm{Br}$ J Biomed Sci 2008;65:90-94.

39. Voorzanger-R oussel ot N, G oehrig D, J ourne F, et al. Increased Dickkopf-1 expression in breast cancer bone metastases. $\mathrm{Br}$ J Cancer 2007;97:964-970.

40. Siddiqua A, Chendil D, R owland R, et al. Increased expression of PSA mRNA during brachytherapy in peripheral blood of patients with prostate cancer. U rology 2002;60:270-275.

41. Ogawa 0 , linuma $M$, Sato K, et al. Circulating prostate-specific antigen mRNA during radical prostatectomy in patients with localized prostate cancer: With special reference to neoadjuvant hormonal therapy. Urol Res 1999;27:291-296.

42. M andel ID. The functions of saliva.J Dent Res 1987;66:623-627.

43. Sreebny LM. Salivary flow in health and disease. Compend Suppl 1989;13:S461-469. 
44. K aufman E, L amster I. The diagnostic applications of saliva: A review. Crit Rev Oral Biol M ed 2002;13:197-212.

45. Streckfus CF, Bigler L. Saliva as a diagnostic fluid. Oral Dis 2002;8:69-76.

46. M alamud D. Saliva as a diagnostic fluid. Br M ed J 1992;8: 207-208.

47. Samaranayake L. Saliva as a diagnostic fluid. Int DentJ 2007;57: 295-299.

48. Fox PC. Salivary enhancement therapies. Caries Res 2004;38: 241-246.

49. Da M ata AD, da Silva M arques DN, Silveira J M , et al. Effects of gustatory stimulants of salivary secretion on salivary $\mathrm{pH}$ and flow: A randomized controlled trial. Oral Dis 2009;15:220-228.

50. Navazesh M. M ethods for collecting saliva. A nn NY A cad Sci 1993;8:72-77.

51. B osker W M , Huestis M A . O ral fluid testing for drugs of abuse. Clin Chem 2009;55:1910-1931.

52. Pink R, Simek J, Vondrakova J, et al. Saliva as a diagnostic medium. Biomed Pap M ed Fac U niv Palacky Olomouc Czech Repub 2009;153:103-110.

53. Roberts KJ, Grusky O, Swanson AN. Outcomes of blood and oral fluid rapid HIV testing: A literature review, 2000-2006. A IDS Patient Care STDS 2007;21:621-637.

54. Giusti L, Baldini C, B azzichi L, B ombardieri S, L ucacchini A. Proteomic diagnosis of Sjögren's syndrome. Expert Rev Proteomics 2007:4:757-767.

55. Sreebny LM , ZhuWX. The use of whole saliva in the differential diagnosis of Sjögren's syndrome. A dv Dent R es 1996;10:17-24.

56. Zimmermann BG, Wong DT. Salivary mRNA targets for cancer diagnostics. Oral Oncol 2008;44:425-429.

57. Di-X ia C, Schwartz P, Fan-Qin L. Salivary and serum CA 125 assays for detecting malignant ovarian tumors. Obstet $\mathrm{G}$ ynecol 1990;8:701-704.

58. K aufman E, Lamster IB. The diagnostic applications of saliva: A review. Crit Rev Oral Biol Med 2002;13:197-212.
59. B aum BJ . Principles of saliva secretion. A nn NY A cad Sci 1993; 694:17-23.

60. Haeckel R, Hanecke P. A pplication of saliva for drug monitoring: $A n$ in vivo model for transmembrane transport. Eur J Clin Chem Clin Biochem 1996;34:171-191.

61. Aps JK, M artens LC. Review: The physiology of saliva and transfer of drugs into saliva. Forensic Sci Int 2005;150:119-131.

62. Halicka HD, B edner E, Darzynkiewicz Z. Segregation of RNA and separate packaging of DNA and RNA in apoptotic bodies during apoptosis. Exp Cell Res 2000;260:248-256.

63. Hasselmann D, Rappl G, Tilgen W, Reinhold U. Extracellular tyrosinase mRNA within apoptotic bodies is protected from degradation in human serum. Clin Chem 2001;47:1488-1489.

64. Ratajczak J, Wysoczynski M, Hayek F, Janowska-Wieczorek A, R atajczak M Z. M embrane-derived microvesicles: Important and underappreciated mediators of cell-to-cell communication. L eukemia 2006;20:1487-1495.

65. Simpson RJ, Lim JW, M oritz RL, M athivanan S. Exosomes: proteomic insights and diagnostic potential. Expert Rev Proteomics 2009;6:267-283.

66. García J M, García V, Peña C, et al. Extracellular plasma RNA from colon cancer patients is confined in a vesicle-like structure and is mRN A-enriched. RNA 2008;14:1424-1432.

67. Yuan A, Farber E, R apoportA, et al. Transfer of microR N A s by embryonic stem cell microvesicles. PL oS One 2009;4:e4722.

68. Skog J, W ürdinger T, van Rijn S, et al. G lioblastoma microvesicles transport RNA and proteins that promote tumour growth and provide diagnostic biomarkers. Nat Cell Biol 2008;10: 1470-1476.

69. Simpson RJ, Jensen SS, Lim JW, et al. Proteomic profiling of exosomes: current perspectives. Proteomics 2008;8:4083-4099.

70. Al-Nedawi K, M eehan B, Rak J. Microvesicles: messengers and mediators of tumor progression. Cell Cycle 2009;8:2014-2018.

71. A haron A, B renner B. M icroparticles, thrombosis and cancer. B est Pract R es Clin H aematol 2009;22:61-69. 